\title{
STRATEGI BUDAYA TOPENG BETAWI: STUDI KASUS NYI MEH, MAESTRO TOPENG BETAWI
}

\section{BETAWI MASK CULTURE STRATEGY: CASE STUDY OF NYI MEH, BETAWI MASK MAESTRO}

\author{
Kiftiawati, Mursalim \\ Fakultas IImu Budaya, Universitas Mulawarman \\ Fakultas IImu Budaya, Universitas Mulawarman \\ Jl. Ki Hajar Dewantara, Gunung Kelua, Samarinda 75123 \\ Pos-el: kiftiawati@fib.unmul.ac.id
}

*) Naskah diterima: 7 April 2020; direvisi: 17 April 2020; disetujui: 20 Mei 2020

\begin{abstract}
Abstrak
Topeng Betawi merupakan kesenian tradisional Betawi yang hingga tahun 1970-an sangat terkenal di masyarakat. Pada tahun 2000-an, kesenian ini redup bahkan terancam punah. Masalah penelitian ini adalah bagaimana strategi yang dilakukan seniman topeng Betawi dalam mempertahankan kesenian tersebut. Tujuan penelitian ini adalah merumuskan sejumlah strategi budaya yang dilakukan untuk mempertahankan kesenian tradisional. Metode penelitian yang dilakukan penulis adalah penelitian lapangan, meliputi wawancara dan observasi lapangan terhadap Nyi Meh, maestro topeng Betawi tahun 1970-an. Penelitian ini merujuk pada teori antropologi budaya yang dikemukakan Koentjaraningrat, Keesing, Malinowski, Ranjabar, Alwasilah, Sendjaja, dan Yunus. Temuan penting penelitian ini adalah idealisme Nyi Meh dalam berkesenian dan melestarikan teater topeng Betawi membawanya pada sejumlah strategi dan sikap dalam menghadapi penghargaan yang tidak memadai dari masyarakat ataupun lembaga pengayom. Hasil penelitian lapangan ini melengkapi tesis Yvone Tri Yoga Hoesodoningsih dan disertasi Ninuk Kleden-Probonegoro mengenai Nyi Meh sebagai kembang (primadona/maestro) topeng Betawi.
\end{abstract}

Kata Kunci: topeng Betawi, strategi budaya, pemertahan budaya

\begin{abstract}
Betawi mask is a Betawi traditional art that until the 1970s was very popular in the community. In the 2000s, this art was dim and even threatened with extinction. The problem of this research is how the strategy used by Betawi mask artists in maintaining the art. The purpose of this study is to formulate a number of cultural strategies undertaken to maintain traditional arts. The method of research conducted by the author is field research including interviews and field observations of Nyi Meh, maestro Betawi mask in the 1970s. This research refers to the cultural anthropology theory proposed by Koentjaraningrat, Keesing, Malinowski, Ranjabar, Alwasilah, Sendjaja, and Yunus. An important finding obtained from this research is Nyi Meh's idealism in performing arts and preserving Betawi mask theater led to a number of strategies and attitudes in the face of inadequate appreciation from the public or the protecting institutions. The results of this field study complement the Yvone Tri Yoga Hoesodoningsih thesis and Ninuk Kleden-Probonegoro's dissertation about Nyi Meh as a Betawi mask flower (excellent/maestro).
\end{abstract}

Keywords: Betawi mask, cultural stategy, cultural maintanance 


\section{PENDAHULUAN}

Pembangunan yang terus diupayakan oleh pemerintah sejak kemerdekaan menemukan titik kemajuan dalam bentuk hadirnya infrastruktur di banyak wilayah, terutama pulau Jawa sebagai sentra pemerintahan. Akan tetapi, kemajuan itu juga menghasilkan sejumlah masalah yang berlimpah di ranah sosial, politik, hukum, kesehatan, ekonomi, etika, dan sebagainya, termasuk budaya.

Pada ranah kebudayaan, masalah tersebut muncul, antara lain, dalam bentuk keterpinggiran budaya lokal. Semangat mengejar kemajuan sering kali dimaknai dengan mengikuti semua hal yang ada di Barat. Akibatnya, kesenian tradisional sedikit demi sedikit mengalami kepunahan. Tidak hanya seni tradisional, Collins bahkan menyebut bahwa bahasa daerah pun mengalami kepunahan justru ketika pemerintah menggalakkan bahasa Indonesia sebagai bahasa nasional (Collins, 2019). Kepunahan bahasa Lampung menjadi contoh konkret hal tersebut.

Tidak dapat dipungkiri, deru pembangunan di Jakarta-baik fisik maupun psikis-dan terjangan globalisasi terus menggerus budaya Betawi. Penggusuran permukiman Betawi pada awal tahun 1990an di sejumlah wilayah untuk berbagai kepentingan - semisal permukiman Betawi di Karet Kuningan, Setia Budi, Jakarta Selatan, yang sekarang menjadi Mall Ambassadortelah menggusur pula kantong-kantong budaya Betawi. Tradisi dan kesenian yang semula tumbuh subur, lengkap dengan ajeknya sistem regenerasi, ikut tergusur pula dan akhirnya perlahan punah. Para penggiat kesenian Betawi satu per satu hilang karena terputus rantai regenerasi. Gempuran globalisasi dan budaya Barat membuat mereka-para penggiat kesenian Betawi-alih profesi karena tidak "laku" lagi. Deru pembangunan telah meming- girkan Betawi, baik secara kultural maupun struktural.

Topeng Betawi sebagai salah satu kesenian tradisional Betawi dalam 30 tahun terakhir ini semakin jarang dipentaskan. Suku Dinas Kebudayaan dan Permuseuman Jakarta memasukkan topeng Betawi dalam kategori rawan atau terancam musnah (2010). Banyaknya agenda pemerintahan daerah dan agenda politik nasional membuat pemerintah provinsi tidak memberi perhatian maksimal pada kesenian Betawi. Lembaga Kebudayaan Betawi dan Dinas Pariwisata Jakarta sebenarnya sudah melakukan banyak pemetaan dan usulan saran. Akan tetapi, agenda yang padat membuat hasil penelitian dan rekomendasi tersebut tidak menemukan realisasi konkret.

Baru di era Gubernur Anies Baswedan, kesenian Betawi yang terancam punah (termasuk topeng Betawi) mendapat perhatian serius, bahkan diberi tempat terhormat melalui program berkelanjutan dan pementasan sejumlah acara besar dan resmi pemerintah provinsi Jakarta.

Pementasan kesenian tradisional Betawi tetap berdenyut walaupun lemah di beberapa titik di luar jantung Jakarta. Salah satu yang bertahan dengan segala keterhuyungan adalah topeng Betawi. Meski terengahengah, kesenian ini tetap hidup dan diminati masyarakat pinggiran Jakarta. Kenyataan ini mendorong tim peneliti untuk mengkajinya secara saksama.

Pembahasan mengenai topeng Betawi sebenarnya telah lama dilakukan. Boen S. Oemardjati menegaskan bahwa sejumlah pementasan seni tradisional memberi pengaruh besar dalam teater modern di Indonesia. Teater Dardanela, pertunjukan lenong, topeng Betawi, ubrug, dan sejumlah pementasan tradisonal menjadi sumber dalam penyusunan naskah dan pementasan teater modern di Indonesia (Oemardjati, 2015). 
Ninuk Kleden-Probonegoro dan Yvone Tri Yoga Hoesodoningsih menyebutkan bahwa R. W. Rittler dan A. Hardouin merupakan pihak pertama yang menyinggung teater topeng Betawi dalam pernikahan orang Betawi melalui tulisan berjudul Java, Tonalen, Uit het Leven, Karakterschetsenen Kleerdragten van Java's Bewoners yang terbit tahun 1855. Pigeaud pada tahun 1938 juga menyinggung teater topeng Betawi dalam pembahasan mengenai seni pentas di Jawa. Keterkaitan antara topeng Betawi dan topeng Cirebon telah dibahas Yulianti Parani pada tahun 1976 (Kleden-Probonegoro, 2015:33).

C. D. Grijn dalam artikelnya berjudul "Distributional Aspect of Folk Performances in Jakarta Malay Area" pada jurnal Masyarakat Indonesia tahun 1981 secara khusus membahas pertunjukan topeng Betawi. Tulisan tersebut kemudian menjadi berharga karena Grijn membuat pemetaan jumlah kelompok pertunjukan topeng Betawi dan merumuskan daerah-daerah yang menjadi pusat topeng Betawi. Berdasarkan daftar hajatan yang menyelenggarakan topeng Betawi, Grijn menemukan bahwa pada tahun 1977 ada lebih dari 20 kelompok topeng Betawi. Pemetaan Grijn sampai pada perumusan bahwa Kecamatan Pondok Gede, Setu, Tambun, Cibitung, Cikarang, Pebayuran, Sukatani, dan Babelan merupakan pusat teater topeng Betawi di Bekasi. Sementara itu, Kecamatan Gunung Putri dan Cileungsi menjadi pusat topeng Betawi di Bogor. Untuk wilayah Jakarta, pusat topeng Betawi berada di Pasar Rebo.

Dalam disertasinya, Kleden-Probonegoro juga menampilkan daftar jumlah kelompok teater topeng Betawi tahun 1975. Data tersebut didasarkan pada data yang dirilis Kanwil Kebudayaan di Jakarta Timur, Bogor, Tangerang, dan Bekasi (KledenProbonegoro, 2015:25). Secara kuantitas, Bekasi merupakan pusat topeng Betawi karena jumlahnya tertinggi, yakni 28 kelompok teater topeng Betawi. Pusat topeng Betawi di Bekasi berada di Kecamatan Tambun dan Babelan. Jakarta memiliki 14 kelompok, Tangerang memiliki 18 kelompok, sedangkan Bogor hanya memiliki 2 kelompok.

Kleden-Probonegoro juga menyebutkan bahwa topeng Betawi semakin dikenal masyarakat umum setelah Srijono Sispardjo membahasnya dalam Kawit, surat kabar dan buletin kebudayaan Jawa Barat. Sispardjo membahas aspek drama dan sastra dalam teater topeng Betawi pada seminar topeng Betawi yang diselenggarakan oleh Dinas Kebudayaan DKI Jakarta tahun 1979. Pembicara lainnya dalam seminar topeng Betawi tersebut adalah Puspita Sari (Fungsi Topeng Betawi bagi Masyarakat Pendukungnya), An Azhar (Aspek Musik Topeng Betawi), dan Rohmad (Aspek Tari Topeng Betawi) (Kleden-Probonegoro, 2015:33-34).

Uraian mengenai rangkaian tulisan tentang topeng Betawi membawa kita pada beberapa temuan menarik. Pertama, tulisan Rittler dan Hardouin tahun 1855 mengenai topeng Betawi menunjukkan bahwa pada tahun tersebut, topeng Betawi sudah populer dan biasa dipentaskan dalam acara hajatan orang Betawi. Artinya, keberadaan topeng Betawi sudah hadir jauh sebelum tahun 1855. Kedua, pemetaan yang dilakukan Grijn tahun 1977 dan Kanwil Kebudayaan tahun 1975 setidaknya menunjukkan bahwa kesenian ini mendapat tempat yang besar dan tersendiri di masyarakat. Hal ini terbukti dengan banyaknya jumlah kelompok teater topeng Betawi yang eksis pada masa itu. Tidak mungkin jumlahnya akan banyak jika masyarakat tidak mendukung, mengapresiasi, dan membesarkannya. Ketiga, Bekasi merupakan daerah yangsetidaknya-sejak tahun 1977 menjadi pusat topeng Betawi. Keempat, penelitian Parani pada tahun 1979 (bahwa topeng 
Betawi memiliki sejumlah keterkaitan dengan topeng Cirebon) membawa kita pada kesimpulan bahwa kehadiran topeng Betawi tidak terlepas dari pengaruh kesenian topeng dari daerah lain.

Uraian pada bagian latar belakang menuntun tim peneliti pada pertanyaan mendasar, bagaimana strategi topeng Betawi bertahan di tengah banyaknya hambatan yang justru menghancurkan eksistensinya.

Berdasarkan rumusan masalah tersebut, tujuan penelitian ini adalah membuktikan bahwa ada sejumlah strategi yang dilakukan seniman topeng Betawi untuk terus bertahan dan melestarikan topeng Betawi di tengah gempuran globalisasi ini.

\section{LANDASAN TEORI}

Koentjaraningrat (2015:146) memandang bahwa kebudayaan akan terus tercipta, dari tempat ke tempat, dari individu ke individu, dan dari masa ke masa. Artinya, kebudayaan akan mengalami perubahan dari waktu ke waktu sehingga masyarakat harus tetap mengenal, memelihara, dan melestarikan kebudayaan yang dimiliki. Perubahan kultural pada dasarnya adalah suatu proses adaptasi dan semacam seleksi alam (Keesing, 2015:87). Kontak budaya yang terjadi pada masyarakat, menurut Malinowski, akan membuat budaya yang lebih tinggi dan aktif akan mempengaruhi budaya yang lebih rendah dan pasif (2015:21).

A.W. Widjaja mengartikan pelestarian sebagai kegiatan yang dilakukan secara terus menerus, terarah, dan terpadu guna mewujudkan tujuan tertentu yang mencerminkan adanya sesuatu yang tetap dan abadi, bersifat dinamis, luwes, dan selektif (Nahak, 2019). Salah satu tujuan pelestarian budaya adalah revitalisasi (penguatan) budaya. Alwasilah merumuskan ada 3 langkah revitalisasi budaya, yakni (1) pemahaman untuk menimbulkan kesadaran, (2) perencanaan secara kolektif, dan (3) pembang- kitan kreativitas kebudayaaan (2014:18). Pada sumber yang sama, Alwasilah menyebutkan bahwa diperlukan strategi dan teknik pelestarian yang yang didasarkan pada kebutuhan dan kondisinya masingmasing.

Menjaga dan melestarikan seni tradisional dapat dilakukan dengan berbagai cara. Sendjaja (1994:286) merumuskan 2 cara, yakni (1) Culture Experience, pelestarian budaya yang dilakukan dengan cara terjun langsung dalam pengalaman kultural, semisal masyarakat dianjurkan belajar dan berlatih menguasai tarian tradisional dan dipentaskan secara berkala pada acara tertentu; (2) Culture Knowledge, pelestarian budaya yang dilakukan dengan cara membuat pusat informasi mengenai kebudayaan yang dapat difungsionalisasikan ke banyak bentuk. Tujuannya adalah untuk edukasi, pengembangan kebudayaan itu sendiri, dan potensi kepariwisataan daerah.

Ranjabar menyebutkan cara lain, yakni mengenal budaya itu sendiri agar pembajakan kebudayaan oleh negara lain dapat diatasi. Di sisi lain, peran pemerintah dalam melestarikan budaya bangsa juga sangat penting. Pemerintah harus mengimplementasikan kebijakan-kebijakan yang mengarah pada upaya pelestarian kebudayaan nasional. Semua itu dilakukan sebagai upaya pengenalan kebudayaan lokal kepada generasi muda, bahwa budaya yang ditampilkan itu adalah warisan dari leluhurnya, berasal dari negara tetangga, demikian juga upaya-upaya melalui jalur formal pendidikan (Ranjabar, 2006:34). Pemerintah juga dapat lebih memusatkan perhatian pada pendidikan muatan lokal kebudayaan daerah. Terkait dengan peran pemerintah, Yunus menambah satu poin penting, yakni pemerintah mendorong masyarakat agar mampu mengelola keanekaragaman budaya lokal (Yunus, 2014: 123). 


\section{METODE PENELITIAN}

Penelitian ini menggunakan metode kualitatif berupa studi pustaka dan observasi lapangan. Studi pustaka dilakukan dalam kaitannya dengan pembahasan para pakar mengenai topeng Betawi dan Nyi Meh. Sejumlah literatur menjadi rujukan dalam penelitian dan penyusunan laporan penelitian ini. Tulisan Grijn, Ninuk KledenProbonegoro, Hoedosoningsih, dan Yahya Andi Saputra menjadi rujukan utama berkaitan dengan topeng Betawi. Studi Pustaka mengenai Nyi Meh merujuk pada penelitian yang telah dilakukan oleh Grijn dan Ninuk Kleden-Probonegoro.

Observasi lapangan dilakukan dalam bentuk wawancara berkaitan dengan data strategi Nyi Meh dalam mempertahankan tradisi topeng Betawi. Wawancara dilakukan langsung oleh peneliti. Narasumber wawancara adalah Nyi Meh dan Bohim yang menjadi pemilik sekaligus penggerak kelompok topeng Betawi "Nyi Meh Putra Adang Grup". Wawancara dilakukan di kediaman Nyi Meh, di Bekasi. Lokasinya berada di Jalan Makrik No. 28 RT 1/5, Rawa Roko, Kelurahan Bojong Rawa Lumbu, Kecamatan Rawa Lumbu, Bekasi.

Hasil wawancara tersebut diolah kemudian dijadikan bahan analisis untuk memetakan strategi yang dilakukan Nyi Meh dalam mempertahankan topeng Betawi. Hasil temuan lapangan tersebut akan dikaji lebih mendalam melalui sejumlah teori kebudayaan yang telah dirumuskan oleh Koentjaraningrat, Keesing, Malinowski, Widjaja, Alwasilah, Sendjaja, Ranjabar, dan Yunus.

\section{HASIL DAN PEMBAHASAN}

\section{Nyi Meh, Kembang Topeng Betawi}

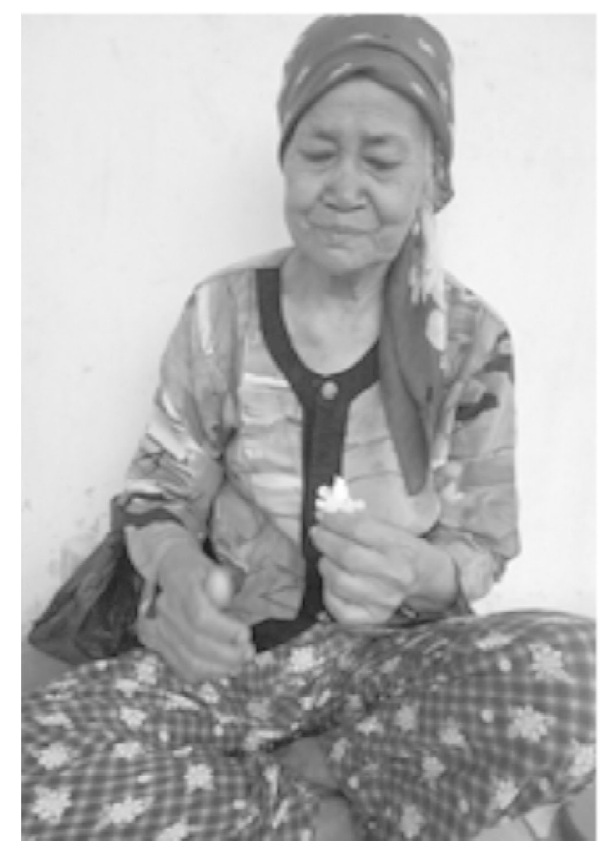

Nama Nyi Meh disebut-sebut Grijn sebagai salah satu nama kembang (primadona) topeng Betawi dan kelompok topeng Betawi yang terkenal tahun 1970-an (Grijn, 1981; 1991). Eksistensi Nyi Meh sebagai kembang topeng juga disebut dalam penelitian Hoesodoningsih. Sebutan yang digunakan Hoesodoningsih adalah ronggeng topeng Betawi (Hoesodoningsih, 2010).

Nama Nyi Meh juga disebut beberapa kali dalam penelitian disertasi KledenProbonegoro. Pertama, ketika menyampaikan kehidupan ronggeng topeng bernama Manol. Nama Nyi Meh disebut sebagai orang yang kemudian menampung Manol dan ibunya dan menjadikan mereka berdua sebagai anggota rombongan kelompok topeng milik Nyi Meh. Pada bagian ini disebutkan bahwa Manol dan ibunya ikut Nyi Meh "ngamen" di sekitar Pasar Mester, Jatinegara. Saat itu, Nyi Meh "ngamen" bersama suaminya, Nasir, seniman terkenal Betawi.

Kedua, Kleden-Probonegoro menyebut nama Nyi Meh ketika menyampaikan 
hubungan keluarga dalam salah satu perkumpulan topeng Betawi. Nama Nyi Meh disebut sebagai istri Jayadi, sang pemilik perkumpulan teater topeng Betawi "Sinar Jaya". Pada bagian ini disebutkan pula bahwa Nyi Meh membawa anak perempuannya bernama Asmeri, buah dari pernikahannya dengan Acim, suaminya sebelum Jayadi. Dengan kata lain, suami pertama Nyi Meh adalah Nasir, seniman besar Betawi. Karena Nasir adalah kakak Mpok Norry, Nyi Meh memiliki hubungan kerabat dengan Mpok Norry sebagai adik ipar.

Setelah berpisah dari Nasir, Nyi Meh menikah dengan Acim dan memiliki anak perempuan bernama Asmeri. Pernikahan kedua ini juga kandas. Nyi Meh kemudian menikah dengan Jayadi. Sayangnya, penelitian Kleden-Probonegoro tidak menyebutkan tahun-tahun pada kedua peristiwa tersebut.

Baik Hoesodoningsih maupun KledenProbonegoro, keduanya tidak membahas secara khusus tentang kepopuleran Nyi Meh. Hoesodoningsih hanya menyebut Nyi Meh sebagai ronggeng topeng yang terkenal. Kleden-Probonegoro menyebut nama Nyi Meh ketika menerangkan sesuatu, yakni tentang Manol dan hubungan kekerabatan dalam perkumpulan topeng Betawi. Hal ini wajar karena keduanya memiliki fokus penelitian tersendiri. Penelusuran literatur penulis mengenai kepopuleran dan kondisi Nyi Meh dahulu dan saat ini tidak menghasilkan informasi apa pun.

\section{Temuan Lapangan}

Nama Nyi Meh sebenarnya kami temukan secara tidak sengaja. Sanggar Seli Asih, sanggar terbesar di Bekasi dan sudah go international, merekomendasikan nama itu ketika kami menanyakan topeng Betawi. Setelah menyusuri pelosok Bekasi, akhirnya kami menemukan Nyi Meh dan sanggarnya.
Lokasinya berada di Jalan Makrik No. 28 RT 1/5, Rawa Roko, Kelurahan Bojong Rawa Lumbu, Kecamatan Rawa Lumbu, Bekasi.

Secara fisik, tidak ada yang istimewa dari sosok Nyi Meh. Usia yang senja membuatnya sama saja dengan nenek-nenek yang lain. Akan tetapi, hampir semua masyarakat Bekasi dan pekerja seni Betawi di Bekasi mengenalnya sebagai maestro topeng Bekasi. Penamaan Bekasi pada topeng Bekasi ternyata hanya merujuk pada identitas kota tempat berkembangnya kesenian tersebut, tidak merujuk pada perbedaan gerakan tari karena tidak ada perbedaan mendasar antara topeng Bekasi dan topeng Betawi.

Kami melakukan wawancara dengan Nyi Meh dan Bohim, pimpinan sanggar "Nyi Meh Putra Adang Group". Sanggar ini merupakan sanggar yang dibentuk sendiri oleh Nyi Meh untuk melestarikan topeng Betawi. Pembicaraan kami dengan Nyi Meh dan Bohim sampai pada beberapa temuan menarik berikut ini.

Kegiatan berkesenian Nyi Meh diawali sejak zaman penjajahan Belanda. Meskipun tidak tahu persis tahun berapa, Nyi Meh menyebutkan bahwa ia sudah menekuni tari dan teater topeng Betawi ketika penjajah Belanda memberlakukan uang tembaga yang tengahnya berlubang (uang tembaga bolong). Jenis kesenian yang digelutinya adalah topeng Betawi. Dahulu, ia menggunakan tari serimpi terutama adegan Rahwana tertawa, dengan menggunakan kedok atau topeng. Kemudian, ia fokus pada ronggeng topeng atau kembang topeng. Keterangannya ini kemudian membawa peneliti pada pandangan bahwa Nyi Meh melakukan kombinasi tari topeng dengan tari dari daerah lain.

Ketika ritual kemenyan dilakukan oleh sebagian besar pemain sandiwara Betawi ataupun penari Betawi sebelum pementasan, Nyi Meh dikenal sebagai satu-satunya 
orang di dunia pertunjukan Betawi yang tidak menjalani ritual tersebut. Secara sadar ia menolak ritual tersebut karena baginya menari harus murni menari, tidak ditambahi ritual apa pun. Baginya, perjanjian dengan setan atau jin melalui ritual bakar kemenyan itu memang akan membuat orang cepat tersohor dan kaya, tetapi umur cepat habis. Semua rekannya yang menggunakan ritual tersebut memang mendapatkan banyak harta, tetapi berakhir dengan mati muda dan tragis. Tanpa ritual itu, nyatanya kiprah Nyi Meh dalam berkesenian tetap dihargai dan digemari masyarakat. Usianya pun panjang. Ia tetap terkenal dan bahkan menjadi primadona dalam tari dan teater topeng Betawi.

"Kancil Putih" merupakan julukan Nyi Meh dalam dunia teater topeng Betawi. Sebutan "Nyi Meh" sendiri merupakan julukannya dalam dunia tari topeng Betawi. Ketenarannya dalam teater topeng Betawi tersohor sampai ke luar daerah Jakarta. Hal ini terlihat dari datangnya beberapa permintaan dari masyarakat Bandung padanya untuk menunjukkan kemampuannya dalam mementaskan tari dan teater topeng Betawi.

Sebagaimana telah disampaikan di bagian sebelumnya, suami pertama Nyi Meh adalah Nasir, seniman terkenal Betawi. Karena Nasir adalah kakak Mpok Norry, Nyi Meh memiliki hubungan kerabat dengan Mpok Norry sebagai adik ipar. Pernikahannya dengan Nasir kandas di tengah jalan dan kedua anaknya meninggal. Setelah bercerai, ia kemudian menikah lagi dan mendapat anak. Jika merujuk pada disertasi Kleden-Probonegoro, suami keduanya adalah Acim, suami ketiganya adalah Jayadi, pimpinan teater topeng Betawi "Sinar Jaya”.

Nama besar mantan suaminya, Nasir, membawa Nyi Meh dan grup bentukannya-"Sanggar Nyi Meh Putra Adang
Group" - menjadi pengisi tetap acara di Taman Mini Indonesia Indah dengan bayaran yang cukup besar untuk ukuran saat itu. Yang mendirikan dan mengetuai sanggar tersebut adalah Nyi Meh sendiri. Ketika usianya semakin lanjut, kepemimpinan sanggar diserahkan pada Bohim, menantunya. Sanggar yang terletak di Jalan Makrik No. 28 RT 1/5, Rawa Roko, Kelurahan Bojong Rawa Lumbu, Kecamatan Rawa Lumbu, Bekasi ini terdaftar di Kantor Wali Kota dan Dinas Pariwisata setempat. Sebagai upaya regenerasi, Nyi Meh - dibantu Bohim - melatih cucu dan cicitnya melawak dan menari.

Sejak awal, Nyi Meh menetapkan orangorang yang menjadi pemain, penari, dan pemusik dalam sanggar ini harus orangorang yang memang memiliki kemampuan bagus. Mereka hanya dilatih di awal saja. Selebihnya, dipanggil beberapa hari sebelum pementasan. Latihan hanya dilakukan ketika akan ada festival dan ada uang transportasinya. Uang ini kemudian menjadi penting bagi sanggar "Nyi Meh Putra" karena para pemain dan penari sanggar ini banyak yang tinggal di tempat yang berjauhan, seperti Kranggan dan Setu, Bekasi. Tuntutan kualitas sebagaimana yang ditetapkan Nyi Meh dan uang transportasi untuk latihan, terutama bagi anggota sanggarnya yang tinggal jauh, menunjukkan pola kepemimpinan dan profesionalisme Nyi Meh sebagai pemilik dan pemimpin sanggar.

Akan tetapi, setelah Nasir meninggal tahun 2006, tarif besar yang biasa didapatnya dari Taman Mini itu berubah drastis menjadi Rp500.000,00/pementasan. Nyi Meh secara tegas memutuskan untuk tidak lagi pentas di tempat itu. Tidak saja karena nominal itu tidak cukup jika harus dibagi dengan 25 orang (pemain dan kru musik) ditambah dengan biaya transportasi dan sewa peralatan, tetapi lebih karena ia me- 
mandang bahwa aktivitas berkeseniannya tidak dihargai sebagai usahanya melestarikan kesenian Betawi. Sikap tegas ini kembali menunjukkan profesionalisme dan kepemimpinan Nyi Meh.

Tarif sanggar "Nyi Meh Putra" berkisar 2,5-3 juta untuk setiap pementasan pada tahun 2000-an. Tarif ini sangat bergantung pada jauh dekatnya tempat pementasan. Jumlah tersebut sudah termasuk dekorasi dan sound system. Sayangnya, peralatan sound system yang mereka sediakan ternyata bukan properti mereka, tetapi milik orang lain yang mereka sewa. Dengan demikian, tarif tersebut masih harus dipotong dengan sewa sound system.

Sebelum tahun 2004, sanggar Nyi Meh Putra tidak memiliki peralatan memadai untuk melakukan pementasan. Baru pada tahun 2004 pejabat di Wali Kota Bekasi mengabulkan permohonan mereka untuk memberikan bantuan peralatan pementasan agar Nyi Meh dan sanggarnya terus melestarikan topeng Betawi di Bekasi. Tahun 2005 dan tahun-tahun berikutnya, Dinas Pariwisata Bekasi meminta mereka mengisi acara di festival kesenian Bekasi. Akan tetapi, sanggar bentukannya mengalami nasib yang sama dengan sanggar-sanggar Betawi lain, sepi order.

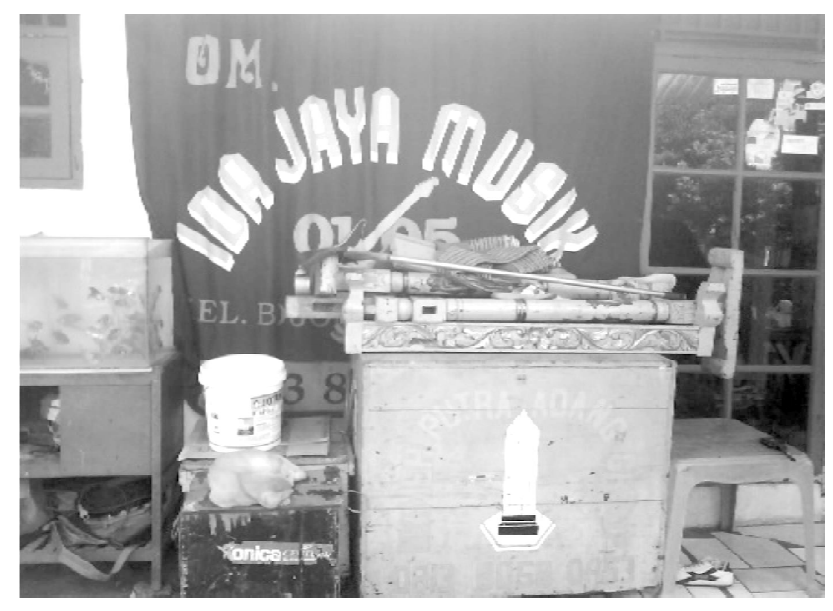

Bantuan alat dari Pemda Bekasi
Mereka hanya pentas pada saat khitanan atau acara resepsi pernikahan dari kampung ke kampung. Itu pun, tidak begitu banyak panggilan karena orang lebih suka mendatangkan orkes dangdut. Untuk memenuhi tuntutan masyarakat dan kebutuhan ekonomi mereka, sanggar ini yang awalnya hanya mementaskan topeng Betawi, akhirnya melayani juga permintaan untuk membawakan lagu-lagu dangdut dengan iringan organ tunggal.

Frekuensi pementasan sanggar ini tidak menentu. Kadang dalam satu bulan mereka pentas 3-4 kali, tetapi kadang kala-dan ini yang sering - tidak ada pementasan sama sekali. Jadwal tetap mereka hanya di bulan Juni sebanyak 3 kali pementasan, bulan Juli 1 kali, dan bulan Agustus - saat perayaan kemerdekaan RI - 1 kali pementasan. Bulanbulan selain itu, mereka sepi order.

Di usianya yang senja, mungkin sekitar 80-90 tahun, tubuhnya masih terlihat kuat dan sigap. Uraiannya tentang sanggar Seli Asih yang didirikan oleh Ki Dalang Naman Jaya, pelopor wayang Betawi, hubungan kekerabatan dan hubungan kerja antara Nasir dan Bokir, juga sanggar-sanggar topeng lain seperti sanggar "Kenjon”, "Mustika Jaya", dan "Sumber Sari" menunjukkan masih kuat ingatannya.

Nyi Meh dan kefasihannya dalam memetakan seni topeng Betawi di Bekasi dan Jakarta. Nyi Meh sendiri hidup prihatin. Dalam rumah petak kecil yang dihuni bersama anak, cucu, dan cicitnya, ia menyambung hidup dengan membuat bunga-bunga kecil. Bayarannya pun sangat mencengangkan, Rp100,00 untuk setiap 1 lusin bunga kecil yang dibuatnya. Ini tentu kenyataan pahit yang harus dihadapinya.

Akan tetapi, itu pilihan yang diambilnya daripada melakukan pementasan sandiwara dan tari topeng tetapi tidak dihargai orang. Membuat bunga-bunga kecil itu kemudian 
menjadi pilihannya meskipun dengan bayaran yang jauh dari manusiawi.

Bagi Nyi Meh, berada di panggung berarti membawakan semangat Betawi dan nilai-nilai agung yang ada di dalamnya, tidak sekadar mencari uang. Keputusan untuk juga melayani permintaan membawakan dangdut hanyalah strategi agar lagu, tari, dan teater topeng Betawi tetap bisa mereka mainkan. Meskipun melayani permintaan lagu dangdut, selalu ada beberapa lagu, tari, dan pentas kecil topeng Betawi yang dilakukan. Sebagian orang barangkali mencibir keputusan tersebut. Akan tetapi, itu merupakan negosiasi Nyi Meh dan sanggarnya karena masyarakat yang mereka hadapi sedang tergila-gila dengan dangdut.

Idealisme ini kemudian membawanya pada sikap pantang mengemis-ngemis pada orang atau lembaga tertentu untuk bisa melakukan pementasan dan mendapatkan uang. Sikap yang sama juga ditampakkan pemimpin sanggar Seli Asih ketika menyikapi kebijakan pemerintah setempat terhadap kesenian Betawi dan sepinya order pementasan.

Berkaitan dengan dangdut, Hoesodoningsih menyebutkan dalam penelitiannya bahwa terjadi perubahan dalam pementasan topeng Betawi. Salah satunya adalah masuknya lagu dangdut yang menuntut sinden, tokoh lelakon, ronggeng, dan alat musik menyesuaikan dengan dangdut dalam pementasan teater topeng Betawi (Hoesodoningsih, 2010:112). Akan tetapi, Nyi Meh dan sanggarnya menghadirkan dangdut terpisah dari pementasan topeng Betawi. Itu sebabnya, sanggar ini memiliki dua nama, yakni Nyi Meh Putra Adang Group untuk pementasan topeng Betawi dan Orkes Melayu Ida Jaya Musik untuk pementasan orkes dangdut.

Dalam penelitian yang sama, Hoesodoningsih menyimpulkan bahwa saat ini to- peng atau kedok tidak lagi digunakan oleh penari dalam teater topeng Betawi karena sejumlah pertimbangan. Penyebabnya adalah karena tidak ada upaya pewarisan ke generasi selanjutnya. Kesimpulan ini justru tidak ditemukan penulis dalam penelitian lapangan. Nyi Meh melatih penari di sanggarnya-terutama anak, cucu, dan cicitnya-menari dengan menggunakan kedok atau topeng. Rekaman video yang penulis dapatkan dari Pak Bohim juga memperlihatkan bahwa dalam pementasan, penari sanggar ini menggunakan topeng atau kedok.

Hal yang sama juga penulis temukan pada sanggar Seli Asih. Eksistensi topeng dan pewarisannya terhadap generasi berikutnya sebagaimana yang dilakukan Nyi Meh dalam sanggar Nyi Meh Putra Adang Group dan sanggar Seli Asih menjadi catatan penting karena berseberangan dengan kesimpulan penelitian Hoesodoningsih.

Zaman yang terik memberi pilihan pada Nyi Meh, sanggarnya, dan sanggar-sanggar lain berupa jalan sunyi dan sepi order ketika bersetia pada kesenian Betawi. Gegap gempita pemilihan Abang None Jakarta dan perayaan ulang tahun Jakarta tidak memberikan perubahan signifikan bagi mereka. Zaman yang terik juga memaksa Nyi Meh menyambung hidup dengan membuat bunga-bunga kecil dengan upah yang tidak manusiawi daripada harus menerima penghargaan yang tidak sepadan. Akan tetapi, zaman yang terik lengkap dengan pilihanpilihan kejamnya mendorong Nyi Meh dan penggiat lain seni Betawi untuk mengemas dan bernegosiasi dengan tuntutan zaman dan justru meneguhkan Nyi Meh dan orangorang yang bersetia pada kesenian Betawi sebagai pejuang kesenian Betawi.

Pendataan yang dilakukan Lembaga Kesenian Betawi (LKB) bekerja sama dengan Dinas Pariwisata dan Kebudayaan Jakarta 
berkaitan dengan pemetaan seni budaya Betawi menemukan kelanjutannya lewat sejumlah penelitian yang dilakukan oleh tim peneliti FIB UI. Hasil penelitian tersebut kemudian menjadi rekomendasi para pengampu kepentingan di pemerintahan daerah untuk mempertahankan, mengembangkan, dan menghidupi kesenian Betawi, termasuk topeng Betawi. Pendirian pusat kebudayaan Betawi di Setu Babakan, Srengseng Sawah menjadi titik balik kebangkitan dalam melestarikan kesenian Betawi. Sejak 10 tahun lalu, tempat tersebut sebenarnya sudah mementaskan kesenian Betawi semisal topeng Betawi, lenong Betawi, dan tanjidor. Akan tetapi, pementasan yang ada baru pada taraf sekadar pentas dengan mempersilakan kelompok kesenian yang masih ada saja. Baru 5 tahun terakhir ini mulai ada pementasan dan diskusi menarik yang dikemas secara serius.

Era pemerintahan Anies Baswedan menjadi bulan madu kebangkitan tersebut. Pembangunan gedung pertunjukan megah di area Setu Babakan yang selama periode gubernur sebelumnya tersendat dan tidak mendapat prioritas, di era Baswedan justru menjadi prioritas utama dalam program budaya Pemerintah Provinsi (Pemprov) DKI Jakarta. Tidak hanya itu, kegiatan yang diselenggarakan di gedung tersebut berfokus pada pementasan dan diskusi yang mengangkat kembali kesenian yang masuk kategori rawan dan terancam punah. Kegiatan tersebut tidak hanya melibatkan seniman Betawi, tetapi juga pelaku seni di ranah sastra Indonesia dan seni pertunjukan.

Kebijakan dan program Pemprov DKI Jakarta tersebut membawa seniman Betawi, termasuk Nyi Meh dan kelompok topeng Betawinya, ke gedung pementasan yang layak dengan penonton yang banyak dan mengapresiasi dengan baik. Kesenian Betawi, dalam hal ini topeng Betawi, men- jadi tuan rumah di tempatnya sendiri, tidak lagi menjadi pelengkap di pinggiran Jakarta. Selain itu, komitmen Pemprov era Baswedan dibuktikan pula melalui pementasan berkala dan pelibatan seniman Betawi, terutama topeng Betawi, dalam banyak acara resmi Pemprov DKI Jakarta. Tidak hanya itu, Pemprov DKI menetapkan program yang berupaya mengenalkan kesenian Betawi di ranah internasional. Bentuk konkretnya bisa kita temukan dalam kegiatan pengiriman kelompok topeng Betawi pada acara festival budaya terbesar Meksiko, Feria Internacional de las Culturas Amigas tahun 2018 (Santi, 2018).

\section{Strategi Budaya dalam Mempertahan- kan Topeng Betawi}

Tidak dapat dipungkiri, topeng Betawi yang pada tahun 1970-an sampai 1980-an menjadi primadona seni pertunjukan di Jakarta dan sekitarnya, pada tahun 1990-an sampai 2000-an mengalami penurunan drastis. Perubahan drastis ini mengonfirmasi teori Koentjaraningrat (2015: 146) dan Keesing (2015:87) bahwa kebudayaan (termasuk di dalamnya seni tari dan teater) akan mengami perubahan, pasang surut, dan mengalami semacam seleksi alam.

Gempuran budaya Barat, perkembangan televisi dan dunia hiburan hanya sebagian kecil penyebabnya. Faktor-faktor ini menunjukkan bahwa pendapat Malinowski $(2015 ; 21)$ tentang pengaruh budaya yang lebih tinggi dan aktif terhadap budaya yang lebih rendah dan pasif, benar adanya.

Uraian berkaitan dengan Nyi Meh dan kiprahnya dalam mempertahankan topeng Betawi menarik untuk dianalisis. Analisis akan berfokus pada fase ketika Nyi Meh mengalami banyak hambatan dalam berkesenian, tetapi berusaha untuk tetap bertahan. Ada sejumlah pola atau strategi yang dilakukan Nyi Meh untuk mempertahankan topeng Betawi. Berikut ini adalah uraiannya. 


\section{Strategi Nyi Meh}

Strategi pertama yang langsung terlihat adalah membentuk sendiri grup topeng Betawi. Terlepas dari pelibatan anak, menantu, cucu, dan cicit yang dimiliki Nyi Meh, langkah ini menjadi upaya konkret karena lewat sanggar yang dibentuknya itu, denyut topeng Betawi tetap ada. Dengan demikian, grup yang dibentuknya menjadi semacam kantong budaya untuk melakukan regenerasi walaupun terhadap keluarganya sendiri.

Temuan lapangan bahwa Nyi Meh juga melibatkan orang lain di luar keluarganya dalam berkarya dan melakukan pementasan membawa kita pada temuan bahwa Nyi Meh tidak semata berfokus pada kerabatnya, tetapi pada kemampuan dan profesionalisme dalam berkarya. Artinya, Nyi Meh tidak segan melakukan kaderisasi pada pekerja seni yang memang serius dalam berkesenian. Informasi bahwa Nyi Meh mengajari mereka merupakan bentuk konkret terkait dengan pengaderan tersebut.

Strategi yang dilakukan Nyi Meh ini sejalan dengan teori yang disampaikan Widjaja (dalam Nahak, 2019). Nyi Meh melakukan kegiatan itu secara terus menerus dan terarah untuk mewujudkan tujuannya, yakni melestarikan dan mewariskan seni topeng Betawi. Kegiatan yang dilakukan di sanggarnya secara konkret menunjukkan adanya usaha untuk membangkitkan kreativitas kebudayaan, dalam hal ini topeng Betawi. Hal ini senapas dengan salah satu dari 3 rumusan revitalisasi budaya yang disampaikan oleh Alwasilah (2014:18). Kenyataan bahwa banyak orang yang dilibatkan Nyi Meh dalam sanggarnya untuk belajar dan mementaskan topeng Betawi menunjukkan bahwa Nyi Meh melakukan strategi yang oleh Sendjaja (1994:286) disebut sebagai culture experience.

Strategi lain yang ditempuh Nyi Meh untuk mempertahankan eksistensi topeng
Betawi adalah menjalin komunikasi yang baik dengan kantong budaya besar semisal Taman Mini Indonesia Indah (TMII) Jakarta. Komunikasi tersebut tidak saja berguna untuk memperoleh jatah pementasan secara berkala, tetapi juga memastikan adanya peluang informasi terbaru mengenai perkembangan kesenian Betawi dan link baru. Strategi ini merupakan cara yang belum dirumuskan dalam teori yang tim peneliti rujuk.

Yang menarik, ketika pamor mantan suaminya, Nasir, menurun dan berdampak pada menurunnya tarif dan frekuensi pementasan di TMII, Nyi Meh bersikap tegas, mengundurkan diri dari pementasan berkala. Keputusan tersebut didorong oleh tarif yang kecil sehingga tidak mungkin menutupi biaya produksi dan munculnya perasaan tidak dihargai. Keputusan ini menunjukkan sikap tegas dan profesional Nyi Meh sebagai maestro topeng Betawi.

Ketika keputusan tersebut mengakibatkan sepinya permintaan untuk melakukan pementasan, yang dilakukan Nyi Meh adalah mencari peluang lain. Strategi menarik yang dilakukan Nyi Meh adalah menerima permintaan untuk menyajikan dangdut, tetapi diselingi dengan tari Betawi, lagu Betawi, ataupun (dengan perkenan pemilik acara) pentas kecil topeng Betawi. Strategi ini menunjukkan bahwa Nyi Meh bernegosiasi dengan keadaan. Nyi Meh bersedia menyajikan dangdut yang memang diminta dan digandrungi masyarakatnya, tetapi ia tetap meminta agar ada sedikit penyajian lagu, tari, ataupun topeng Betawi. Pada titik ini kita bisa melihat bagaimana Nyi Meh berusaha menyisipkan seni Betawi, terutama topeng Betawi di setiap permintaan pentas yang ia dapatkan.

Strategi ini mengonfirmasi apa yang dirumuskan Keesing (2015:87) dengan nama perubahan kultural dan proses adaptasi. Strategi yang dilakukan Nyi Meh menunjuk- 
kan bahwa ia melakukan negosiasi dengan tuntutan dan perubahan yang ada di masyarakat. Yang patut diapresiasi adalah negosiasi itu tetap dalam kendali Nyi Meh, yakni memenuhi permintaan menghadirkan dangdut, tetapi tetap harus ada penyajian lagu, tari, dan topeng Betawi.

Tidak berlebihan jika langkah tegas dalam negosiasi ini mencerminkan upaya Nyi Meh untuk melakukan apa yang disebut Sendjaja (1994:286) sebagai culture knowledge, yakni menjadikan sanggarnya tetap menjadi pusat informasi dan pelestari topeng Betawi.

Hal menarik lain yang dapat kita rumuskan sebagai strategi adalah keengganan $\mathrm{Nyi}$ Meh untuk asal pentas, menolak tegas ketika diminta murni menampilkan dangdut, apalagi mengemis kesempatan pentas pada lembaga besar yang ada di Jakarta dan Bekasi. Sikap yang sama juga peneliti jumpai pada sanggar Seli Asih yang sudah go international. Merangkai bunga meski dengan bayaran yang tidak seberapa menjadi pilihan Nyi Meh ketika tidak ada permintaan untuk melakukan pementasan meskipun dengan tarif yang tidak manusiawi. Pada titik ini kita sampai pada temuan bahwa strategi tersebut merupakan cermin dari ketegasan, idealisme dalam berkesenian, dan profesionalisme dalam berkarya. Artinya, nama besar Nyi Meh sebagai maestro topeng Betawi juga dibarengi dengan idealisme dan profesionalitas dalam berkarya. Ini tentu sangat berharga mengingat ada begitu banyak seniman tradisional yang kemudian banting setir menjadi pemain sinetron dan turut menciptakan image negatif tentang Betawi yang cenderung malas, materialis, tidak kreatif, kasar, dan selalu merepotkan orang lain.

Kenyataan bahwa pekerja seni di Bekasi juga masyarakat Bekasi mengenal Nyi Meh sebagai maestro topeng Betawi menunjukkan bahwa Nyi Meh cukup dihormati.
Banyaknya penonton yang hadir di setiap pementasannya menunjukkan pula bahwa topeng Betawi yang dipentaskannya cukup berkualitas dan disukai masyarakat. Artinya, Nyi Meh memiliki gaya, pengemasan, dan kreativitas yang menarik perhatian masyarakat. Hadirnya humor dalam salah satu babak pentas topeng Betawi menjadi daya tarik masyarakat terhadap kesenian ini. Kreativitas Nyi Meh ini sejalan dengan rumusan revitalisasi budaya yang dikemukakan Alwasilah (2014:18).

Tidak berlebihan jika kita menyimpulkan bahwa harumnya nama Nyi Meh di masyarakat karena kualitas karyanya, strategi pengemasan yang menarik, juga idealismenya dalam berkarya. Sikap tegasnya untuk tidak mengemis-ngemis pementasan pada lembaga besar meneguhkan idealisme tersebut. Sikap ini agaknya yang kemudian membuat Pemprov Bekasi dan Jakarta memberinya berbagai peluang, seperti bantuan sound system dan alat pementasan, uang pembinaan berkala, dan pentas di panggung besar pada acara pemprov. Keaktifan sanggar Nyi Meh dalam sejumlah pelatihan dan acara terkait kesenian Betawi juga bisa kita rumuskan sebagai strateginya dalam menjalin kerja sama dan memperluas jejaring kesenian.

\section{Strategi Eksternal}

Pada akhirnya, semua strategi tersebut tidak akan memberi banyak arti ketika tidak ada peran dari masyarakat pendukung, lembaga pendidikan, patron budaya, dan pemerintah setempat. Kenyataan bahwa selalu ada masyarakat yang menggunakan jasa Nyi Meh dan sanggarnya untuk mementaskan topeng Betawi menunjukkan bahwa masyarakat masih menaruh minat dan mendukung kesenian ini.

Patron budaya Betawi juga memiliki peran penting dalam mempertahankan dan mengembangkan topeng Betawi. Patron yang dimaksud, antara lain, Lembaga 
Kebudayaan Betawi. Lembaga ini melalui penelitian lapangan telah melakukan pemetaan seni budaya Betawi dan memberikan sejumlah rekomendasi konkret pada para pengampu kepentingan semisal Dinas Kebudayaan Jakarta (Saputra, 2013).

Lembaga pendidikan menjadi garda terdepan dalam penelitian berkaitan dengan budaya Betawi. Penelitian yang dilakukan Muhadjir dkk. (2012) menjadi pembuka penelitian yang berkaitan dengan seni budaya Betawi. Penelitian ini dilakukan pada tahun 1987 lalu disempurnakan pada tahun 2000. Penelitian yang dilakukan oleh tim peneliti budaya Betawi FIB Universitas Indonesia tahun 2009-2011 mejadi titik awal kebangkitan penelitian tentang budaya Betawi. Sejumlah penelitian di berbagai ranah budaya Betawi dapat ditelusuri (Tim Peneliti Budaya Betawi, 2010; 2011). Kajian ilmiah terbuka lebar, temuan baru berhasil dirumuskan, dan sejumlah rekomendasi pelestarian siap dieksekusi pemerintah daerah.

Pada akhirnya, kesungguhan pemerintah daerah dalam merealisasikan hasil penelitian dan sejumlah rekomendasi menjadi kunci dari semua itu. Program Anies Baswedan untuk menjadikan Betawi sebagai tuan rumah di kotanya sendiri patut diapresiasi. Program tersebut tidak sekadar jargon sebagaimana gubernur sebelumnya, tetapi menemukan bentuk konkret dalam banyak hal, semisal percepatan pembangunan gedung megah untuk pementasan kesenian tradisional Betawi di Setu Babakan, pementasan berkala dan diskusi pementasan, program pembinaan kualitas seniman Betawi, hingga pementasan kesenian Betawi, termasuk topeng Betawi, di acara resmi Pemprov DKI Jakarta.

Merujuk pada teori yang sampaikan Ranjabar (2006:34) dan Yunus (2014:123), apa yang dilakukan Pemprov DKI Jakarta merupakan langkah konkret pemerintah daerah dalam mengimplementasikan kebijakan-kebijakan yang mengarah pada upaya pelestarian kebudayaan nasional dan mendorong masyarakat agar mampu mengelola keanekaragaman budaya lokal.

Semua uraian ini membawa kita pada pemahaman penting. Idealisme dan profesionalisme seniman tradisional merupakan hal yang sangat penting dalam mempertahankan tradisi yang ada. Akan tetapi, diperlukan sinergi yang bagus antara seniman, masyarakat pendukung, lembaga pendidikan, patron budaya, dan pemerintah setempat dalam mempertahankan budaya lokal, dalam hal ini topeng Betawi.

Kenyataan bahwa Kalimantan Timur akan menjadi ibu kota negara tidak menutup kemungkinan bahwa yang terjadi pada kesenian Betawi akan terjadi pada kesenian Dayak. Tentu, kita tidak mengharapkan hal itu terjadi. Akan tetapi, ibu kota memiliki begitu banyak agenda dan prioritas di tingkat nasional. Akibatnya, kesenian lokal sering kali terabaikan dan tidak mendapat perhatian yang memadai. Sebelum hal itu terjadi, harus ada sinergi antara seniman tradisi, masyarakat pendukung, lembaga pendidikan, patron budaya, dan pemerintah setempat.

\section{PENUTUP}

Berdasarkan analisis pada bagian pembahasan di atas, penelitian ini menarik kesimpulan sebagai berikut. Pertama, penelitian lapangan yang penulis lakukan sampai pada temuan bahwa Nyi Meh tetap membina sanggarnya meskipun hidup dalam keprihatinan. Idealismenya berkesenian dan melestarikan teater topeng Betawi membawanya pada sejumlah strategi dan sikap dalam menghadapi penghargaan yang tidak memadai dari masyarakat ataupun lembaga tertentu. Hasil penelitian lapangan ini melengkapi tesis 
Hoesodoningsih dan disertasi Ninuk Kleden-Probonegoro mengenai Nyi Meh sebagai kembang topeng Betawi.

Kedua, strategi yang dilakukan Nyi Meh dalam melestarikan topeng Betawi adalah mempertahankan idealisme dan profesionalitasnya dalam berkarya, menjalin komunikasi yang baik dengan kantong budaya atau patron budaya besar, bernegosiasi dengan keadaan (memenuhi permintaan masyarakat, tetapi tetap menyelipkan tari dan topeng Betawi), dan mempertahankan kualitas karya dengan pengemasan yang menarik.

Ketiga, harus ada sinergi antara seniman tradisi, masyarakat pendukung, lembaga pendidikan, patron budaya, dan pemerintah setempat untuk mempertahankan seni tradisi.

Strategi yang dilakukan Nyi Meh mengonfirmasi teori yang dirumuskan oleh Koentjaraningrat, Keesing, Malinowski, Widjaja, Alwasilah, Sendjaja, Ranjabar, dan Yunus.

\section{DAFTAR PUSTAKA}

Alwasilah, Adeng Chaedar. 2014. Islam, Culture, and education: Essays on Contemporary Indonesia. Bandung: Rosda Karya.

Collins, James T. 2019. "Language Death in Indonesia: Crisis and Interdisciplinary Collaboration". Kuliah Umum di FIB UI, 10 Oktober 2018. Makalah tidak diterbitkan.

Grijn, C. D. 1991. Jakarta Malay. Leiden: KITLV Press, 1991.

- - - "Distributional Aspect of Folk Performances in Jakarta Malay Area", Masyarakat Indonesia, jilid VIII, No. 2 Jakarta: LIPI, 1981.

Hoesodoningsih, Yvone Tri Yoga. 2010. "Seni Pertunjukan Betawi, Kontinuitas dan Perubahannya". Tesis. Fakultas
Ilmu Sosial Ilmu Politik. Universitas Indonesia.

Keesing, Roger Martin. 2015. Antropologi Budaya: Suatu Perspektif Kontemporer. Jakarta: Erlangga.

Kleden-Probonegoro, Ninuk. 2015. “Topeng Betawi sebagai Teks dan Maknanya, Suatu Tafsiran Antropologi". Disertasi. Universitas Indonesia.

Koentjaraningrat. 2015. Pengantar Ilmu Antropologi, Sejarah Teori Antropologi. Jakarta, Rineka Cipta.

Malinowski, Bronislaw. 2015. Scientific Theory of Culture and Other Essay. Chapel Hill: The University of North Carolina Press.

Muhadjir dkk. 2012. Peta Seni Budaya Betawi. Jakarta: Dinas Kebudayaan DKI Jakarta. Nahak, Hildigardis M. I. 2019. “Upaya Melestarikan Budaya Indonesia di Era Globalisasi". Jurnal Sosiologi Nusantara, vol. 5 , no. 1 .

Oemarjati, Boen S. 2015. Bentuk Lakon dalam Sastra Indonesia. Jakarta: Gunung Agung. Ranjabar, Jacobus. 2006. Sistem Sosial Budaya Indonesia, Suatu Pengatar. Bandung: Ghalia Indonesia.

Santi, Natalia. “Topeng Betawi di Festival Meksiko" dalam https:// www.cnnindonesia.com/internasional/ 20180418113053-134-291644/tari-topengbetawi-di-festival-budaya-meksiko, diakses 20 Oktober 2019, pukul 19.00.

Saputra, Yahya Andi dan Nurzain. 2013. Profil Seni Budaya Betawi. Jakarta: Lembaga Kebudayaan Betawi dan Dinas Pariwisata dan Kebudayaan Provinsi DKI Jakarta.

Sendjaja, S. Djuarsa. 1994. Teori Komunikasi. Jakarta, Universitas Terbuka.

Suku Dinas Kebudayaan dan Permuseuman DKI Jakarta. https:// www.jakarta.go.id.disbudmudeum/ 
senitradi.htm., diakses 21 Oktober 2019, Yunus, Rasid. 2014. Nilai-Nilai Kearifan Lokal pukul 09.00.

(Local Genius) Sebagai Penguat Karakter

Tim Peneliti Kebudayaan Betawi FIB UI. Bangsa, Studi Empiris Tentang Hayula. 2010. Betawi dalam Seni Sastra dan Seni Yogyakarta: Budi Utama.

Suara di DKI Jakarta. Depok: FIB UI.

- - . 2011. Langgam Budaya Betawi.

Depok: FIB UI. 